\title{
Structural properties of AIN films deposited by plasma-enhanced atomic layer deposition at different growth temperatures
}

\author{
Mustafa Alevli ${ }^{*}$ Cagla Ozgit, Inci Donmez, and Necmi Biyikli** \\ UNAM, Institute of Material Science and Nanotechnology, Bilkent University, 06800 Ankara, Turkey
}

Received 21 July 2011, revised 26 October 2011, accepted 3 November 2011

Published online 29 November 2011

Keywords ALD, AlN, decomposition limited growth, self-limiting growth

* Corresponding author: e-mail alevli@unam.bilkent.edu.tr, Phone: +90-312-2903551, Fax: +90-312-2664365

**e-mail biyikli@unam.bilkent.edu.tr, Phone: +90-312-2903556, Fax: +90-312-2664365

Crystalline aluminum nitride (AlN) films have been prepared by plasma-enhanced atomic layer deposition (PEALD) within the temperature range from 100 to $500{ }^{\circ} \mathrm{C}$. A self-limiting, constant growth rate per cycle temperature window (100$200{ }^{\circ} \mathrm{C}$ ) was established which is the major characteristic of an ALD process. At higher temperatures $\left(>225^{\circ} \mathrm{C}\right)$, deposition rate increased with temperature. Chemical composition, crystallinity, surface morphology, mass density, and spectral refractive index were studied for AlN films. X-ray photo- electron spectroscopy (XPS) analyses indicated that besides main $\mathrm{Al}-\mathrm{N}$ bond, the films contained $\mathrm{Al}-\mathrm{O}-\mathrm{N}, \mathrm{Al}-\mathrm{O}$ complexes, and $\mathrm{Al}-\mathrm{Al}$ metallic aluminum bonds as well. Crystalline hexagonal AlN films were obtained at remarkably low growth temperatures. The mass density increased from 2.65 to $2.96 \mathrm{~g} / \mathrm{cm}^{3}$ and refractive index of the films increased from 1.88 to 2.08 at $533 \mathrm{~nm}$ for film growth temperatures of 100 and $500{ }^{\circ} \mathrm{C}$, respectively.
1 Introduction The growth of III-nitride thin films with well-controlled film thickness down to the subnanometer scale, chemical stability, and suitable step coverage is necessary for the integration of III-nitride devices with the mature silicon CMOS technology. Realization of III-V semiconductor on Si platform would permit to create chip-to-chip and system-to-system optical communications and enable the fabrication of electrically pumped light sources. Aluminum nitride (AlN) has attracted significant attention because of its high thermal conductivity $(320 \mathrm{~W} / \mathrm{mK}$ at $300 \mathrm{~K})$, high electrical resistance $\left(10^{13} \Omega \mathrm{cm}\right)$, high thermal expansion coefficient, and wide and direct optical band gap $(\sim 6.2 \mathrm{eV})[1-3]$. Furthermore, its compatibility with III-V compounds makes AlN promising for the fabrication of band-gap engineered $\mathrm{Al}_{x} \mathrm{Ga}_{y} \mathrm{In}_{1-x-y} \mathrm{~N}$-based optoelectronic devices [4], high-frequency electro-acoustic devices, and piezoelectric actuators and sensors [5]. As a result of these material properties, a significant amount of research has been devoted to the growth and characterization of AlN thin films [6-9]. While high-temperature (typically above $1100{ }^{\circ} \mathrm{C}$ ) grown epitaxial AlN films are used in active electronic and opto-electronic device layers, polycrystalline and amorphous AlN films grown at CMOS-compatible temperatures (lower than $300^{\circ} \mathrm{C}$ ) are widely used as dielectric and passivation layers for microelectronic devices [10].

In recent years, atomic layer deposition (ALD) with remote plasma capability is a promising growth technique which not only reduces the film growth temperature, but satisfies critical conformality and sub-monolayer thickness control as well $[11,12]$. In this work, we explored the influence of the growth temperatures on the crystallinity, composition, surface roughness, mass density, and refractive index of AlN films grown by plasma-enhanced ALD (PEALD). The growth of AlN films at different growth temperatures $\left(100-500^{\circ} \mathrm{C}\right)$ have been studied by several groups based on PEALD growth method [13-15]. However, in those reports, either self-limiting growth with temperature-dependent growth rate per cycle was observed $[13,14]$ or the resulting films were amorphous within the selflimiting window [15]. In our work, we report crystalline AlN thin films grown at temperatures as low as $100^{\circ} \mathrm{C}$. We carried out systematic experiments to study the influence of growth temperature on the crystalline quality of AlN within the 
range of $100-500{ }^{\circ} \mathrm{C}$. Self-limiting growth with constant growth rate per cycle and temperature-dependent growth rate regimes as well as decomposition-limited growth regime were characterized in detail.

2 Experimental Aluminum nitride films were deposited on $\mathrm{Si}(100)$ substrates at growth temperatures ranging from 100 to $500{ }^{\circ} \mathrm{C}$ by using a Fiji LL Cambridge Nanotech ALD reactor equipped with a remote inductively coupled rf-plasma source and base pressure of 0.2 Torr. Trimethylaluminum (TMA) and ammonia $\left(\mathrm{NH}_{3}\right)$ enhanced by rf-plasma were used as precursors while Ar was used as the carrier gas. During all growth experiments, $\mathrm{NH}_{3}$ gas flow rate was $50 \mathrm{sccm}$ and exposure time was $40 \mathrm{~s}$, TMA pulse time was $0.1 \mathrm{~s}$, purge time in between precursor pulses was $10 \mathrm{~s}$, and plasma power was maintained at $300 \mathrm{~W}$. To investigate the effect of the growth temperature on the AlN film properties $\sim 100 \mathrm{~nm}$ thick AlN layers were deposited at $100,185,400$, and $500{ }^{\circ} \mathrm{C}$.

Film thickness and refractive index were estimated by using a variable angle spectroscopic ellipsometry (SE) at three angles of incidence $(\Psi(65,70,75), \Delta)$. The index of refraction and thickness of each AlN films were extracted from SE data by using the Cauchy dispersion function. X-ray reflectivity (XRR) and grazing incidence $\mathrm{X}$-ray diffraction (GIXRD) measurements with a Philips X'pert PRO MRD diffractometer using $\mathrm{Cu} \mathrm{K} \mathrm{K}_{\alpha}$ radiation were carried out to determine the crystallinity, mass density, and thickness of the deposited films. The elemental profiles, chemical bonding states, and impurity incorporation of the films were determined by X-ray photoelectron spectroscopy (XPS) operating at monochromatized $\mathrm{Al} \mathrm{K}_{\alpha}$ wavelength. Surface morphology and roughness were determined by atomic force microscopy (AFM). High-resolution transmission electron microscopy (HR-TEM) imaging was performed by Tecnai G2 F30 TEM (FEI). Cross-sectional TEM specimens were prepared by focused ion beam (FIB Nova 600i Nanolab - FEI).

3 Results and discussion Initially, the self-limiting growth window $\left(100^{\circ} \mathrm{C}<T_{\text {growth }}<225^{\circ} \mathrm{C}\right)$ for AlN films was obtained by precisely adjusting the deposition temperature, reactant dose, and length of the precursor pulses, in which each surface reaction step is saturative. In this ideal case, chemisorption of each reactant occurs on the surface of the growing film where all the gas-phase reactions are automatically eliminated. Within this window, overdosing precursors and increasing the growth temperature does not affect the growth rate and AlN material was produced with sub-monolayer thickness control [11]. In the subsequent experiments, the growth temperature was increased up to $500{ }^{\circ} \mathrm{C}$ in order to investigate the properties of AlN films in the temperature dependent growth region $\left(T_{\text {growth }}>225^{\circ} \mathrm{C}\right)$. The experimental results are summarized in Fig. 1, where self-limited and temperature dependent growth regimes are indicated.

We explored the influence of growth temperatures on the properties of AlN films by using the aforementioned self-

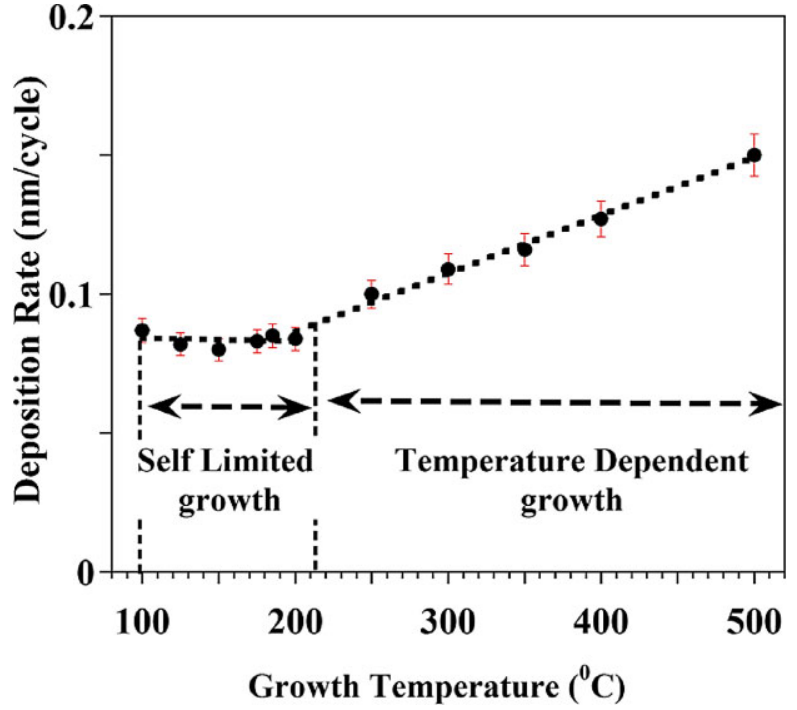

Figure 1 (online color at: www.pss-a.com) Deposition rates of AlN films at different temperatures. Depositions occur in two different temperature windows: self-limited growth window and temperature dependent growth window.

limiting growth condition parameters. Figure $2 \mathrm{a}$ and $\mathrm{b}$ shows the evolution of narrow scan XPS spectra of $\mathrm{N} 1 s$ and $\mathrm{Al} 2 p$ spectra for different growth temperatures taken in the inner layers of AlN, respectively. Three distinct chemical states were observed for AlN films; the Al2p\#1 subpeak at $73.5 \pm 0.1 \mathrm{eV}, \mathrm{Al} 2 p \# 2$ at $72.4 \pm 0.1 \mathrm{eV}$ and $\mathrm{Al} 2 p \# 3$ at $\sim 74.5 \mathrm{eV}$. According to the Al2 $p$ XPS results and dominating Al2p\#1 subpeak, AlN was formed in all samples for all growth temperatures including $100^{\circ} \mathrm{C}$. An Al2p\#3 subpeak is obtained for AlN films grown at 100 and $500{ }^{\circ} \mathrm{C}$ which is correlated to $\mathrm{Al}-\mathrm{O}$ bound states [16]. In the intermediate growth temperatures, Al2 $p \# 2$ subpeak is detected whose binding energy $(\mathrm{BE})$ is clearly related to the $\mathrm{BE}$ of metallic $\mathrm{Al}-\mathrm{Al}$ bond in $\mathrm{AlN}$ [1]. The intensity of $\mathrm{Al} 2 p \# 1$ subpeak was always more than the Al2p\#2 and Al2p\#3 subpeaks at all growth temperatures except $100^{\circ} \mathrm{C}$. However, the O1s XPS analysis of AlN grown at $100^{\circ} \mathrm{C}$ reveal a dominant subpeak at $531.5 \pm 0.1 \mathrm{eV}$. Harris et al. [17] assigned the origin of this oxygen defect to oxygen bound to aluminum (Al-O) with a high coordination number and would be associated with oxygen defects within the AlN crystal columns. This can be also explained with dominating characteristic of $\mathrm{Al} 2 p \# 2$ subpeak and shifting of Al2p\#1 subpeak to higher binding energies. The $\mathrm{O} 1 s$ subpeak analysis for AlN films grown at $500^{\circ} \mathrm{C}$ reveals a major subpeak at $531.8 \pm 0.2 \mathrm{eV}$, which is a characteristic of $\mathrm{Al}-\mathrm{O}$ bonding [16].

Additional information about the chemical structure of the AlN films is provided by the N $1 s$ spectra analysis. On the basis of the deconvolution of N1s XPS peak, the strongest peak at $396.3 \pm 0.3 \mathrm{eV}$ which was detected for all AlN films, is a typical $\mathrm{N}-\mathrm{Al}$ bond [16]. The almost-negligible peak at $398 \pm 0.3 \mathrm{eV}$ is attributed to $\mathrm{AlO}_{x} \mathrm{~N}_{y}[3,16]$. The Al-O-N peak was observed to decrease in intensity as the growth temperature increased, where the peak disappeared at higher 


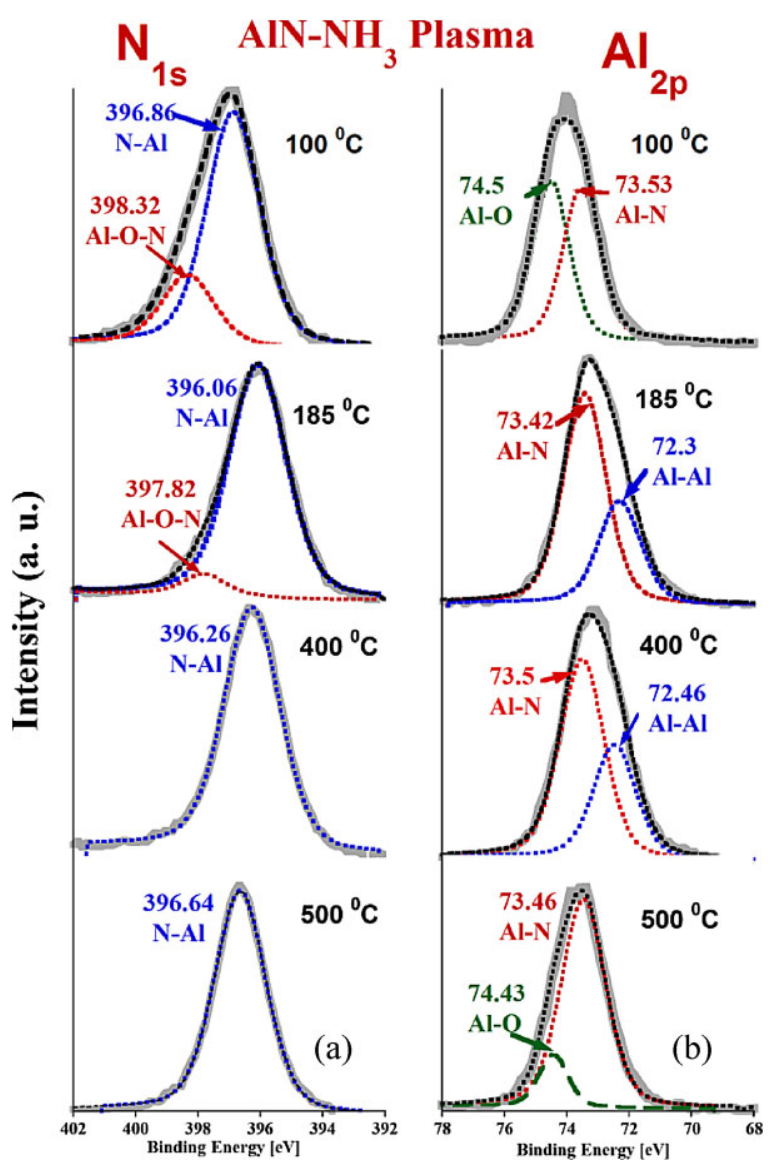

Figure 2 (online color at: www.pss-a.com) High-resolution XPS spectra of (a) N1s and (b) Al $2 p$ peaks of PEALD grown AlN films with different growth temperatures. $\mathrm{AlO}_{x} \mathrm{~N}_{y}$ impurities were observed only in low temperatures.

growth temperatures. In the literature, possible H-related defects were observed and reported using XPS. Formation of possible $-\mathrm{NH}_{x}$ residues such as $\mathrm{AlN}-\mathrm{NH}_{x}$ which have binding energies of 398.5-399.9 eV were not observed in our films [3]. A high resolution of very weak $\mathrm{O} 1 s$ core level peak was analyzed as well and there was no $\mathrm{OH}$ peak from 532.2 to $532.3 \mathrm{eV}$ [18]. Furthermore, we did not observe any $\mathrm{H}$ related impurities based on structural experiments presented in this paper. On the other hand, our samples include metallic aluminum and oxygen impurities. Therefore, at the current stage, discussing the possible effects of $\mathrm{H}$ in the films without performing ERD-TOF and RBS experiments might result in misleading conclusions.

In Fig. 3, the GIXRD profiles of the thin films grown at different temperatures are presented. The thin films exhibited prevalence of a highly polycrystalline hexagonal AlN structure perfectly matching with the XRD Bragg diffraction peak positions corresponding to the literature.

Grazing incidence X-ray diffraction patterns reveal no change in phase and crystalline orientation with temperature. Similar GIXRD patterns were obtained for all AlN films deposited at different growth temperatures and no other impurity related GIXRD pattern observed such as $\mathrm{Al}(111)$ at

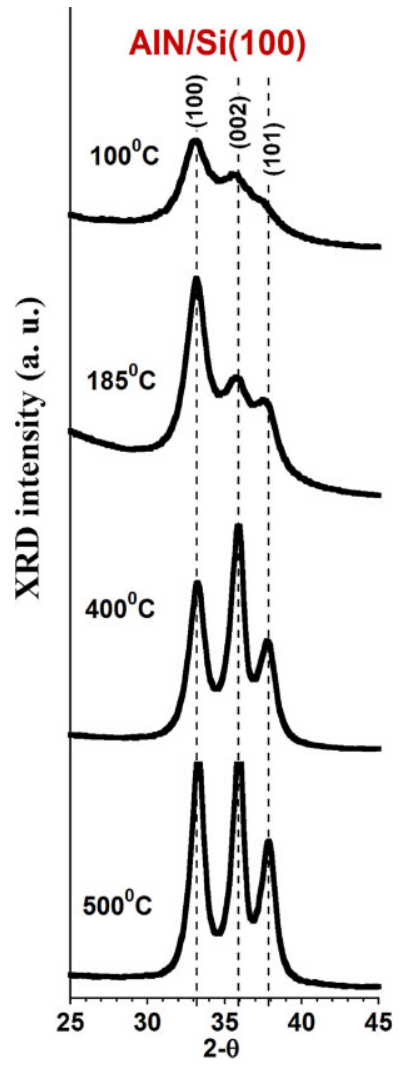

Figure 3 GIXRD patterns for AlN films at different growth temperatures on $\mathrm{Si}(100)$ with the growth parameters obtained in the self-limiting growth window.

$2 \Theta=38.5^{\circ}$ and $\mathrm{Al}(200)$ at $2 \Theta=44.7^{\circ}$. The $h$ - $\mathrm{AlN}(100)$ peak is dominant for the samples grown at low temperatures in the self-limiting growth window. The dominance of (101) and (002) becomes more significant in the GIXRD patterns of AlN films grown at higher growth temperatures. The GIXRD of AlN samples grown at 185,400 , and $500{ }^{\circ} \mathrm{C}$ suggest a higher degree of crystallization which is in good agreement with mass density and refractive index values (see Fig. 6). Upon decreasing the growth temperature down to $100^{\circ} \mathrm{C}$, AlN films possess their crystalline structure. GIXRD results show that the onset temperature for crystalline growth is below $100^{\circ} \mathrm{C}$.

Cross-sectional HR-TEM images of the grown AlN films deposited by PEALD on Si substrates are shown in Fig. 4. We observed that the AlN films consist of self-organized $\mathrm{nm}$-long hexagonal crystalline structures, i.e. (100), (111), (002), etc. which confirms the GIXRD data.

Selected area electron diffraction pattern (SAED) of these films contain continuous rings which are obtained from the large number of diffracted spots (not included in this paper). Continuous diffraction rings obtained from SAED patterns also indicate a polycrystalline nature of AlN films. Analysis of HR-TEM images show that the size of crystalline ordering becomes longer in length and width as the growth temperature increases and the degree of disordering decreases accordingly. 


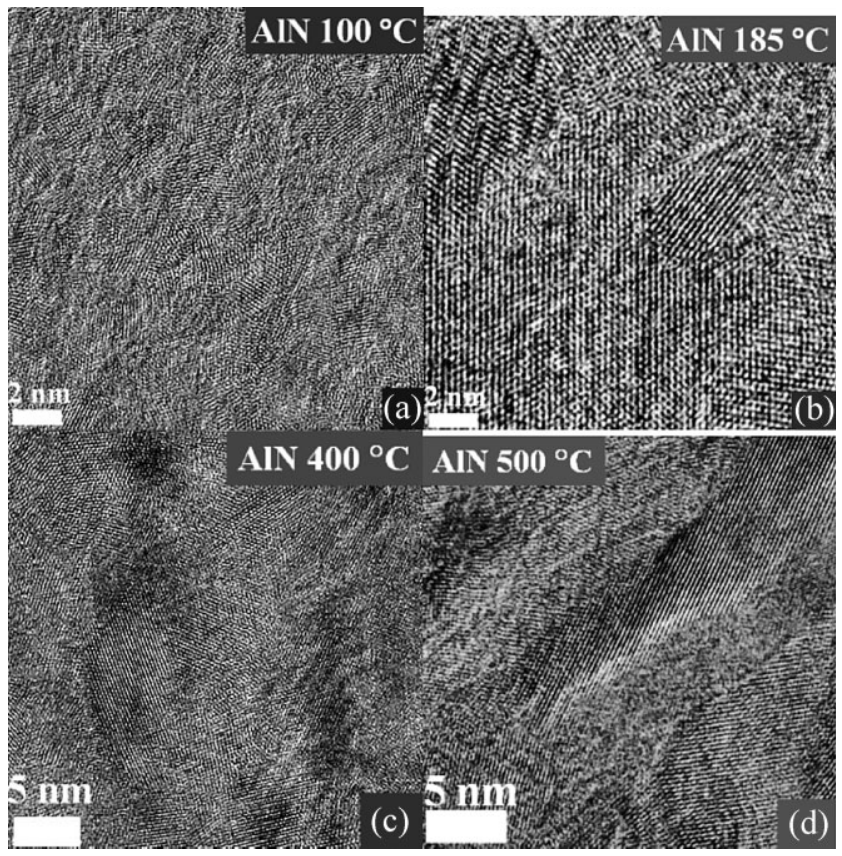

Figure 4 Cross-sectional high-resolution TEM images of $100 \mathrm{~nm}$ thick AlN films grown on $\mathrm{Si}(100)$ substrate at different temperatures.

To access surface morphological information, AFM images were acquired for different size areas on the surfaces of the AlN layers. In Fig. 5, the panels a, b, c, and d demonstrate the AFM images of AlN films grown at growth temperatures $100,185,400$, and $500{ }^{\circ} \mathrm{C}$, respectively. We observed that the surfaces of AlN films become rougher as substrate temperature increases. This is attributed to the larger crystal grains embedded in the films [19]. Root mean square (rms) roughness values measured are relatively high for the films grown at higher growth temperatures with 400 and $500{ }^{\circ} \mathrm{C}\left(2.54 \mathrm{~nm}\right.$ for $400{ }^{\circ} \mathrm{C}$ and $2.16 \mathrm{~nm}$ for $\left.500{ }^{\circ} \mathrm{C}\right)$. The

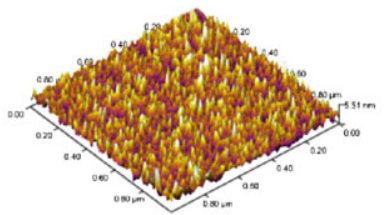

(a) $100^{\circ} \mathrm{C}$

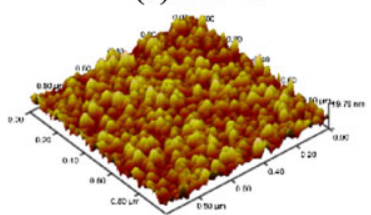

(c) $400{ }^{\circ} \mathrm{C}$

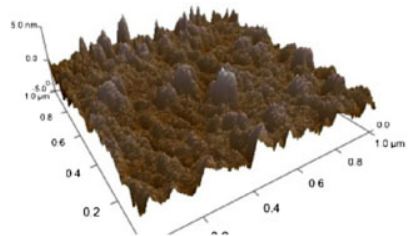

(b) $185^{\circ} \mathrm{C}$

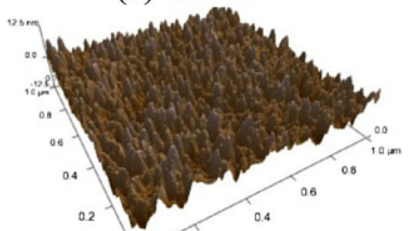

(d) $500^{\circ} \mathrm{C}$
Figure 5 (online color at: www.pss-a.com) Surface morphology of AlN films grown at (a) $100{ }^{\circ} \mathrm{C}(1 \mu \mathrm{m} \times 1 \mu \mathrm{m})$, (b) $185^{\circ} \mathrm{C}$ $(1 \mu \mathrm{m} \times 1 \mu \mathrm{m}), \quad$ (c) $400{ }^{\circ} \mathrm{C}(1 \mu \mathrm{m} \times 1 \mu \mathrm{m})$, and (d) $500{ }^{\circ} \mathrm{C}$ $(1 \mu \mathrm{m} \times 1 \mu \mathrm{m})$. surface of the sample grown at low temperatures is smoother $\left(1.37 \mathrm{~nm}\right.$ for $185^{\circ} \mathrm{C}$ and $0.93 \mathrm{~nm}$ for $\left.100^{\circ} \mathrm{C}\right)$. The surface reaction kinetics and growth mechanisms for the films grown in $100-200{ }^{\circ} \mathrm{C}$ is different compared to samples grown at higher temperatures as aforementioned in Section 3.

Within the temperature-dependent growth regime, precursor self-decomposition occurs for $T>300{ }^{\circ} \mathrm{C}$ which destroys the self-limiting growth mechanism and sub-monolayer thickness control, leading to films with higher surface roughness. Film density, surface roughness, and mean grain size results obtained for different growth temperatures measured with XRR and AFM analysis are shown in Fig. 6. The density, roughness, and mean grain size increased with increasing growth temperature. However, rms roughness decreased for samples grown at $500{ }^{\circ} \mathrm{C}$ compared to samples grown at $400^{\circ} \mathrm{C}$ (Fig. 6b). This might be due to the increased adatom mobility with increasing growth temperature up to $500^{\circ} \mathrm{C}$ which enables surface diffusion and increases coalescence probability of nucleation centers (more CVD-like growth) [20]. XRR results confirm the similar roughness values and similar behavior with growth temperature (Fig. 6). On the other hand, the grain size of AlN film grown at $100^{\circ} \mathrm{C}$ is larger than the ones grown at $185^{\circ} \mathrm{C}$ (see Fig. 6c). Since AlN films grown at $100^{\circ} \mathrm{C}$ contain $\mathrm{Al}-\mathrm{O}$ and $\mathrm{Al}-\mathrm{O}-\mathrm{N}$ complexes according to

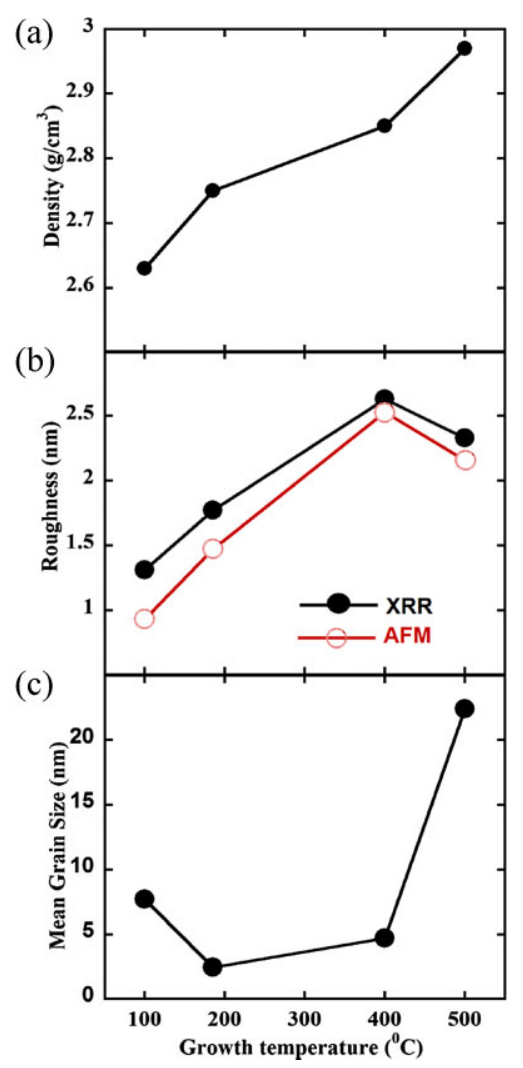

Figure 6 (online color at: www.pss-a.com) (a) Density derived from XRR, (b) roughness measured by AFM and derived from XRR, and (c) mean grain size derived by analyzing AFM images of the AlN films. 
the XPS analysis, grain size and roughness values might have changed not accordingly with AlN films grown at higher temperatures that have less or no $\mathrm{Al}_{x} \mathrm{O}_{y} \mathrm{~N}_{1-x-y}$ related impurities.

Figure 7 shows the index of refraction for AIN films grown at different growth temperatures obtained from Cauchy dispersion model (300-1000 nm). Refractive index $n$ increased with growth temperature from 1.94 to 2.08 at $533 \mathrm{~nm}$ wavelength when the growth temperature increased from 185 to $500{ }^{\circ} \mathrm{C}$. A lower refractive index value 1.87 at $533 \mathrm{~nm}$ is observed for AlN film grown at $100^{\circ} \mathrm{C}$. The extracted refractive index values are in good agreement with polycrystalline AlN reported in literature [21] and confirms our GIXRD and HR-TEM results. The most probable reason for the lower refractive index value might be $\mathrm{Al}-\mathrm{O}$ complexes and higher oxygen concentrations which were also obtained from XPS analysis. The origin of oxygen incorporation is still under investigation. The gases used in the experiments (ammonia and argon) are of ultra-high purity $(99.999 \%)$. There is no leak within the reactor chamber, as confirmed by standard ALD null-tests. However, the oxygen contamination might originate from the Ar carrier gas or $\mathrm{NH}_{3}$ plasma/group-V precursor gas themselves, which contain certain trace amounts of humidity and oxygen impurities.

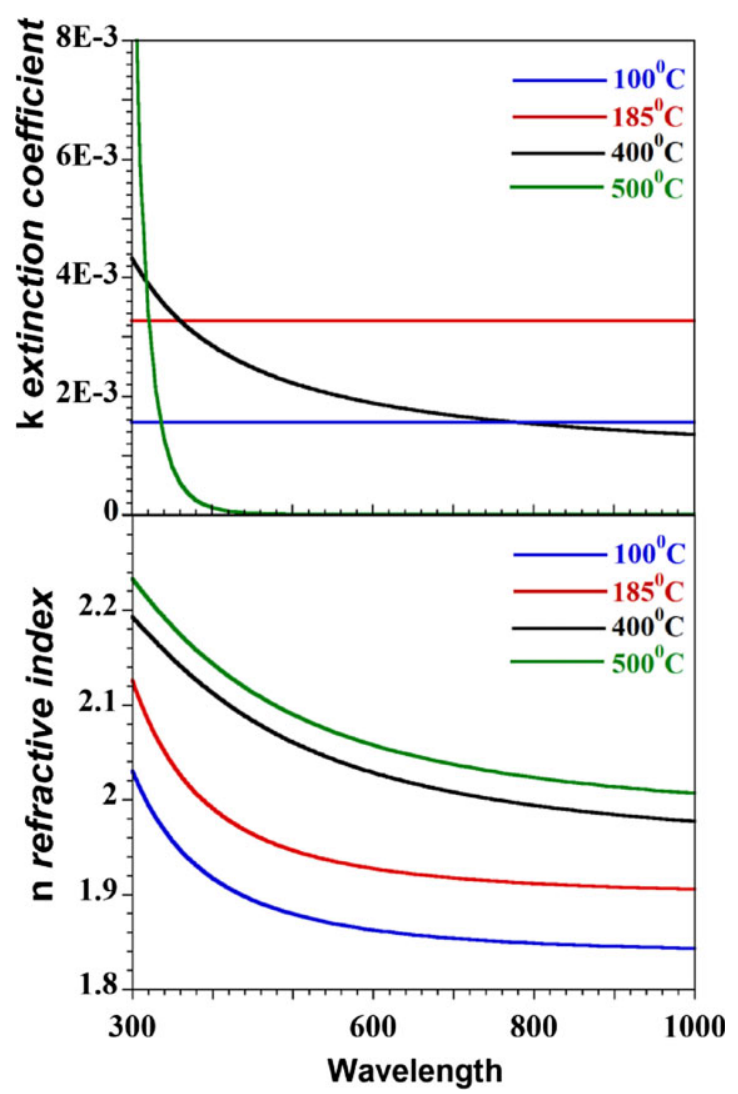

Figure 7 (online color at: www.pss-a.com) Refractive index and extinction coefficient of AIN films grown at different growth temperatures as a function of wavelength.
The refractive index of the AlN films grown with higher temperatures $\left(\geq 185^{\circ} \mathrm{C}\right)$ are in the range of $1.9-2.1$ for observed wavelength range. The extinction coefficient $k$ increases significantly when the wavelength is less than $400 \mathrm{~nm}$ for samples grown at higher temperatures (400 and $500{ }^{\circ} \mathrm{C}$ ) but does not increase even at $300 \mathrm{~nm}$ for samples grown at lower temperatures. The spectral behavior of $k$ extinction coefficient showed a weak dependence for AIN films grown at low temperatures but reasonable dependence for samples at higher temperatures.

4 Conclusions In summary, we have studied PEALD grown crystalline AIN films in two main growth regimes: self-limited growth regime where growth rate per cycle stays constant with temperature and temperature-dependent growth regime where growth rate increases with deposition temperature. The structural properties were significantly affected by the growth temperature. Compared to previously published results, AlN films grown within low-temperature self-limited regime showed significantly improved crystalline quality, higher refractive index and film density, and lower surface roughness. We owe these improved results to the truly self-limiting conditions achieved which eliminate gas-phase reactions and provides ultimate sub-monolayer thickness control. Both structural and optical analyses showed that hexagonal crystalline AIN thin films were obtained at growth temperatures as low as $100^{\circ} \mathrm{C}$ by PEALD. AlN films were composed of nm-sized crystallites of wurtzite planes. Crystalline quality was further improved with higher growth temperatures, where decomposition limited growth occurred and CVD-like growth kinetics dominated. Oxygen was detected as a major impurity in the films. With increasing temperature metallic Al and Al-N-O bonding disappeared and only $\mathrm{Al}-\mathrm{O}$ peak remained at the highest growth temperature. With increased growth temperature, the refractive index increased, which was attributed to the densification of the films. The mass density increased from 2.65 to $2.96 \mathrm{~g} / \mathrm{cm}^{3}$ and refractive index of the films increased from 1.88 to 2.08 at $533 \mathrm{~nm}$ for film growth temperatures of 100 and $500{ }^{\circ} \mathrm{C}$, respectively.

Acknowledgements This work was performed at UNAM supported by the State Planning Organization (DPT) of Turkey through the National Nanotechnology Research Center Project. N.B. acknowledges support from Marie Curie International Reintegration Grant (grant \# PIRG05-GA-2009-249196). M.A. gratefully acknowledges the financial support from TUBITAK (project No.: 232.01-660/4835).

\section{References}

[1] S. Schoser, G. Brauchle, J. Forget, K. Kohlhof, T. Weber, J. Voigt, and B. Rauschenbach, Surf. Coat. Technol. 103/104, 222-226 (1998).

[2] D. Riihela, M. Ritala, R. Matero, M. Leskela, J. Jokinen, and P. Haussalo, Chem. Vap. Depos. 2, 277 (1996).

[3] Y. Lee and S. Kang, Thin Solid Films 446, 227 (2004).

[4] Y. Taniyasu, M. Kasu, and T. Makimoto, Nature 441, 325 (2006). 
[5] H. Joo, H. Kim, S. Kim, and S. Kim, J. Vac. Sci. Technol. A 17, 862 (1999).

[6] F. Hajakbari, M. M. Larijani, M. Ghoranneviss, M. Aslaninejad, and A. Hojabri, Jpn. J. Appl. Phys. 49, 095802 (2010).

[7] Z. Chen, S. Newman, D. Brown, R. Chung, S. Keller, U. K. Mishra, S. P. Denbaars, and S. Nakamura, Appl. Phys. Lett. 93, 191906 (2008).

[8] L. Lahourcade, E. Bellet-Amalric, E. Monroy, M. Abouzaid, and P. Ruterana, Appl. Phys. Lett. 90, 131909 (2007).

[9] C. Mirpuri, S. Xu, J. D. Long, and K. Ostrikov, J. Appl. Phys. 101, 024312 (2007).

[10] M. Bosund, P. Mattila, A. Aierken, T. Hakkarainen, H. Koskenvaara, M. Sopanen, V. M. Airaksinen, and H. Lipsanen, Appl. Surf. Sci. 256, 7434 (2010).

[11] H. Kim, J. Vac. Sci. Technol. A 21, 2231 (2003).

[12] M. Ritala and M. Leskela, in: Handbook of Thin Film Materials, Vol. 1, edited by H. S. Nalwa (Academic Press, New York, 2002).
[13] M. Bosund, T. Sajavaara, M. Laitinen, T. Huhtio, M. Putkonen, V. M. Airaksinen, and H. Lipsanen, Appl. Surf. Sci. 257, 7827 (2011).

[14] X. Liu, S. Ramanathan, E. Lee, and T. E. Seidel, Mater. Res. Soc. Symp. Proc. 811, D.19.1-6 (2004).

[15] K. Kim, N. Kwak, and S. Lee, Electron. Mater. Lett. 5, 83 (2009).

[16] L. Rosenberger, R. Baird, E. McCullen, E. Auner, and G. Shreve, Surf. Interface Anal. 40, 1254 (2008).

[17] J. H. Harris, R. A. Youngman, and R. G. Teller, J. Mater. Res. 5, 1763 (1990).

[18] R. Dalmau, R. Collazo, S. Mita, and Z. Sitar, J. Electron. Mater. 36, 414 (2006).

[19] Y. W. Goh, Y. F. Lu, Z. M. Ren, and T. C. Chong, Appl. Phys. A 77, 433 (2002).

[20] D. Chiba, K. Takamura, F. Matsukara, and H. Ohno, Appl. Phys. Lett. 82, 3020 (2003).

[21] S. Venkataraj, D. Severin, R. Drese, F. Koerfer, and M. Wuttig, Thin Solid Films 502, 235 (2005). 